\title{
Neo-industrialization as the Bases of the Innovative Trajectory of the Development of Russian Industry before and during the Coronavirus Disease-19 Pandemic
}

\author{
Irina O. Malykhina ${ }^{1}$, Victoria N. Riapuhina ${ }^{1 *}$, Elena N. Chizhova ${ }^{1}$, Irina V. Rozdolskaya ${ }^{2}$ \\ ${ }^{1}$ Belgorod State Technological University V. G. Shukhov, Belgorod, Russia; ${ }^{2}$ Belgorod University of Cooperation, Economics \\ and Law, Belgorod, Russia
}

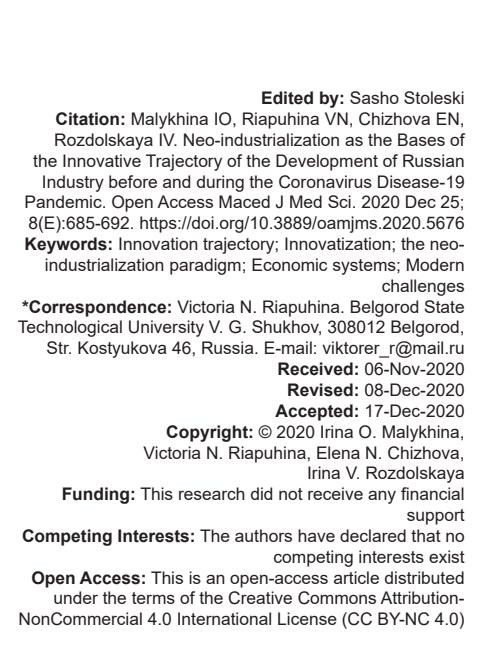

Abstract

BACKGROUND: This article is devoted to the study and improvement of theoretical approaches to the formation of the neo-industrialization paradigm as the basis of the innovative trajectory of the development of economic systems. The relevance of this study is due to the growing importance of neo-industrialization policies as an objective basis for the transition of the Russian economy to an innovative type.

AIM: The aim of the work is the theoretical justification and development of scientific and practical recommendations for the implementation of the innovative trajectory of the development of economic systems in the conditions of neoindustrial challenges.

METHODS: We conducted a literature review of relevant scientific publications. We analyzed and synthesized theoretical concepts. This way, we pointed out the conceptual foundations of the formation of the neo-industrialization paradigm. Using the inductive method, parameters and principles of Russian industry innovative development before and during the coronavirus disease pandemic are define. We used Rosstat data of innovative goods circumference and current innovation expenditures for structural and functional analysis.

RESULTS: The analysis is made and the most important parameters of the formation of the neo-industrialization paradigm are identified. Modern trends, critical neo-industrial challenges, and threats to the innovative development of economic systems are structured, refined, and typologized. The most effective instruments of state participation in enhancing innovation processes in the context of neo-industrial challenges have been consolidated.

CONCLUSION: A paradigm concept for the innovation of economic systems in the context of the implementation of neo-industrialization policies has been formed as a response to modern challenges and threats.

\section{Introduction}

Current situation for the development of the world economic system determine the determining effect of new knowledge and critical technologies on the process of economic development, since it is the results of intellectual activity that has the potential to implement an innovative scenario. Now a days, the development of the Russian economy, as well as the global one, is taking place in difficult geopolitical and socio-economic conditions caused by the spread of the new coronavirus infection coronavirus disease of 2019 (COVID-19), which has de facto suspended (partially or completely) the state's vital processes. The prevailing conditions could not but affect the economic processes. Thus, production volumes fell sharply, which triggered the oil crisis, exacerbated by the Organization of the Petroleum Exporting Countries (OPEC) + deal between oil exporting countries and other large hydrocarbon fuel producers that are not official OPEC members. However, there is no doubt about the need for further implementation of the chosen course of forming an innovative scenario for the development of the Russian economy, with particular emphasis on the implementation of the neo-industrialization paradigm as an objective basis for this development. "First of all, the neo-industrialization strategy is a strategic response to the changing world industrial pattern and a gesture of accepting the logics of free market capitalism" [1].

We emphasize that the Russian economy today is not ready to completely abandon the export-raw material model. This is due to many internal problems of socio-economic, technical, technological, personnel, and other nature. Moreover, the impact of external factors leading to an increase in geopolitical tension and sanction pressure on our country determines the importance of implementing a neo-industrialization policy designed to create favorable conditions for increasing the innovative activity of economic systems, increasing industrial efficiency as a bastion of implementing modernization software solutions in locomotive sectors, and compliance modern requirements of scientific and technological progress, including as part of the concept of "Industry 4.0" [2], [3], [4], [5], [6]. 


\section{Theoretical Framework of Neo-industrialization Concept}

The relevance of the methodological basis and applied solutions to implement the innovative trajectory of the development of economic systems is also due to the manifestation of modern neo-industrialization trends. "Neo-industrialization and innovative growth has not been limited to core regions" [7]. The most important theoretical, methodological, and methodological approaches used to study the problems and prospects of innovative development of the economy in the context of neo-industrialization policies are substantively disclosed in the writings of such scientists as John Bell, Merton Miller, Franco Modigliani, Stephen Alan Ross, Nikolai Dmitrievich Kondratiev, and others.

In recent years, the problem of neoindustrialization has occupied a significant place in the theoretical studies of Russian scientists [8], [9], [10], [11], [12]. Neo-industrialization from the perspective of an analysis of the institutional foundations is disclosed in the writings of O.S. Belokrylova, S.S. Gubanova, A.I. Amosova, S.A. Zhironkina, Yu.A. Kovalchuk, A.A. Kuklina, A.I. Tatarkina, G.G. Fetisova, G.N. Grodskoy, E.S. Valyaeva, S.A. Zhironkina, M.A. Hasanova, V.G. Zaretskaya, I.K. Titkova, I.V. Zernova, L.A. Proshkina et al. Structural and functional analysis of the stages of technological development of the economy in the context of solving the problems of the formation of methodological tools for neo-industrialization was carried out in the works of I.S. Belovoi, V.V. Akberdina, A.V. Alyoshina, L.S. Belyaeva L.V. Krasnyuk, L.G. Matveeva, A.V. Martynova, A.S. Molchan, R.M. Nizhny Novgorod, A.Yu. Nikitaeva, Yu.M. Osipova, V.G. Popova, Yu.V. Razvadovskoy, O.A. Romanova, V.I. Savinkova, M.N. Strikhanova, E.D. Streltsova, G.F. Tokunova, S.A. Tolkacheva, I.K. Shevchenko, O.T. Shipkova, I.A. Edacy et al.

Some Western scientists are not a separate subject of research from neo-industrialization, but it is considered in the mainstream of theories of cyclical development of the economy (Joseph Schumpeter, Gerhard Gerhard Mensch), theories of system development (Lundwall Bengt-Oke), and management theories (Peter Drucker and Michael Eugene Porter). This can be explained by the fact that when the concept of "neo-industrialization approach" first became the subject of discussion among specialists, in contrast to theoretical and methodological aspects, applied problems of forming an innovative trajectory of economic systems development came to the fore [13]. At the end of the period of intensive post-military industrialization of the 60s, a paradigm shift was caused, first of all, by the question of the survival of the real sector of the economy, but these changes did not proceed smoothly. "This attitude did not change until the mid-80, when local actors started to rely less on the past and adopted a more proactive approach. Perhaps the changes came so slowly because the traditional strong ties between government and industry had become detrimental to innovation and flexibility... Economic, institutional, and cognitive lock-in was the result of a consensus culture a traditional of strong coalition of between government, institutions, and industries - combined with an overoptimistic view of the future... For a long time, the individuals concerned did not want to believe that the character of the changes in the region was structural rather than cyclical, but in the middle of the 1980s they recognize the failure of the old politics and moved from the re-industrialization to neo-industrialization. Neoindustrialization has so far proved more viable than previous industrialization strategies" [14].

We may say that in terms of the neoindustrialization paradigm, there are several views. "There are important differences between these new centers of innovation growth; differences in form and formation processes, in thetrajectories thatwerefollowed, in the role of the state, markets, and the cooperative networks that have sustained their development. In our opinions, there are three major routes toward neoindustrialization and innovative development, each of which combines distinctive geographical features and strategic approach" [7]. The first approach, in which large-scale transnational or national business becomes the initiator of development, is based on neo-Taylorism. Moreover, it is characterized by a tendency to flexible forms of internal organization, elasticity of employment in the labor market, forms of direct organization of labor according to Taylor, mass production. As part of this approach, the traditional industrial environment is decentralized, and agreements between companies act as the basis for a competitive strategy. Neo-Taylorism leaves social institutions a secondary place, due to which they are represented quite fragmentarily. The second approach is based on the concept of "sunrise development" and implies the leading role of innovators, small and medium-sized high-tech enterprises focused on the production of high-tech products, organizations involved in research and development (R\&D), and universities. Moreover, in terms of regulating the direction of industrial development of the region, state authorities play the role of creating favorable conditions and centers of attraction for innovative businesses. The third, corporatist approach to neo-industrialization based on the flexible organization of the socio-economic system involves going beyond the industrial cluster to develop the paradigm of openness of the system and the active coexistence of the community. At the same time, there is a segmentation of the economic activity of firms specializing in any particular stage of industrial production. Moreover, the institutional regulation is carried out by the alliances themselves, without the presence of large firms on the market. Considering the East Asian paradigm, we note that "As the comparative advantages thinking has been an inherent component of 
the neo-industrialization strategy, neo-industrialization is as much a state initiative of creating more jobs for domestic needs as a capitalist-oriented policy" [1].

\section{Methods}

In the framework of this study, general scientific methods of cognition were used, namely, the method of analysis, synthesis, induction, structural, and functional analysis. The article develops theoretical concepts and conceptual foundations of the formation of the neoindustrialization paradigm as the basis for the innovation of the Russian economy. The foreign and Russian experience of the formation and implementation of an innovative model for the development of economic systems with the elimination of specific characteristics of the implementation of innovative processes is studied.

\section{Results}

COVID-19 outbreak naturally impacted declines in industrial production. Along with the consequences of the epidemic themselves and the restrictive measures of national governments, it was effect by falling oil prices and the depreciation of the rouble. Oil production level fixed the $100.3 \%$ for the month of April, 2020 vis-à-vis April, 2019 but immediately fell by $15.3 \%$ in May due to the OPEC and Russia Agree to Cut Oil Production. The IPEM (Institute for Natural Monopolies, URL: http:// www.ipem.ru/) - production index decreased by $3.4 \%$ compared to November, 2019 (IPEM calculates the indices is based on indirect integral indicators - electricity consumption and loading of goods on railroad transport. The calculation is not based on the aggregation of primary data but uses an alternative method - an analytical calculation based on basic macroeconomic indicators). Since March, 2020, the output decline did not sharp, but inertially due to the ManufactureTo-Stock. The industries have been affected by the Quarantine Measures to a much lesser deeply than the trade and services. Furthermore, in March, the industry maintained moderately negative trends that had formed back in 2019. Indicators such as rail loading and energy consumption also showed negative trends in the industry. A drop in rates and a decrease in loading in 2020 led to Russian Railways revenues decreased by 158 billion rubles compared to 2019 .

The four groups of industries that experienced the acute phase of the crisis in different ways have been identified based on the indicators of the Federal State Statistics Service (Rosstat, URL: https:// showdata.gks.ru/report/274128/): The most affected, moderately affected, not suffered, and the winners (Industrial production index, January-November 2020 to January-November 2019, by the Rosstat). The industries production of auto and other vehicles, household appliances, furniture, jewelry, sporting goods, and leather goods are the most affected group. There were multiple decreases in output here in April, and the rise in May only partially compensated for the failure. In April, in annual terms declined the production of jewelry $(76.4 \%)$, household appliances $(69.5 \%)$, and automotive (60.2\%). In May, the indicators partially compensated for the decline, but production remained at a low level: In the jewelry industry $-35.6 \%$ of last year, in vehicles $-57.8 \%$, and in household appliances $-74.9 \%$

The industrial production in a group of moderately affected has declined $<30 \%$ in annual terms in April, and there was a quick compensation in May - up to $80-90 \%$ of the level of May 2019. The group consisted of the production of materials, components, machinery and equipment, and non-food consumer goods. Many sectors to recover were helped by delivery development. The strongest decline in the group was in the manufacturers of electrical equipment, the smallest in the rubber, and plastic products.

The group of industries that practically did not suffer from the crisis included food production, paper production, gas production, power generation, and chemical production. Their output level in AprilMay remained relatively stable due to stable demand, economists explain. The most successful in this group were food manufacturers, which increased production by $3.7 \%$ in April and $1.5 \%$ in May, and the chemical industry, which grew by $2.4 \%$ in April and $4.2 \%$ in May.

Production grew at a good pace in just two industries that benefited from the coronavirus crisis. These are pharmaceuticals, which increased output by $13.5 \%$ year-on-year in April and $22.4 \%$ in May, and production of medical instruments and equipment grew by a modest $2.7 \%$ in April and a whopping $33.6 \%$ in May.

\section{Discussion}

The issues of innovative development of economic systems are widely researched and actively studied by both foreign and Russian researchers. Moreover, more and more attention is being paid to the issue of theoretical and scientific-practical substantiation of the implementation of the neo-industrialization paradigm as an objective basis for the innovation of economic systems at various levels of the hierarchy. Russian scientists and economists [15], [16] argue that it is advisable to study the process of neo-industrialization in the context of implementing state industrial policy 
with the aim of modernizing and transforming the manufacturing sector of the economy, while Western researchers prefer to consider it in a slightly different context. "In the line with the developments on the state level, it was decided to focus on innovation instead and to setup the local technology transfer centers providing advice and services to starters" [17].

Neo-industrialization as a system is an economic system built on new knowledge, technologies, and intellectual capital, which is able to efficiently use advanced digital technologies for the emergence of new means of production to achieve a high level of welfare of the population and socio-economic development of the society [18] "By community-based neo-industrialization, we have in mind of process of industrialization in which a modern outward-looking industry develops in a symbiotic relation with same existing community: The industry succeeds where others may not because it is able to draw on the peculiar intimacy of some closeknit community. This is an intimacy that makes life more pleasant within the community and makes contracts between members of community easy to enforce" [19]. Such Russian and foreign scientists researching the problems of neo-industrialization of the economy as [20], [21], [22], [23] consider this phenomenon from several positions: First, as a system; second, as a process; third, as a mechanism; and fourth, as a strategy.

According to Tolkachev, neo-industrialization should be studied as a priority as "the process of large-scale implementation of a set of breakthrough technologies in the manufacturing industry, which results in Tolkachev [24]: A partial change in the paradigm of production activity; integrated continuous electronic control of the extended production cycle of products, allowing you to switch to the cyberphysical type of production; a new stage of production robotization, which allows organically combining the labor of machines and humans." Moreover, Bell [25], Doroshenko et al. [26], Krasnyuk [27], Sushkova [28] consider neo-industrialization as a mechanism for the formation of a new type of economic system that can use the latest tools of scientific and technological progress, manage the development of the industrial sector taking into account modern challenges. We agree with the statement that "the neo-industrial strategy the local parties pursued since the mid eighty was not only novel in terms of its focus on regional renewal. Furthermore, the way of the approach toward structural change was organized different from the past" [17].

Neo-industrialization as a strategy is aimed at creating the conditions for economic growth based on the potential of technical, technological, investment, financial, and innovative development [29]. One of the solutions to the investment and realization of neoindustrialization can be through PPP (public-private partnerships) [30], [31], [32]. "In this context, the neoindustrialization strategy is a conceptual framework, trying to make reconciliations between self-determined development and the domination of global market system, and to adjust between labor-dependent and export-driven economic growth and long-term capacitybuilding efforts of developing pillar industries" [1].

Taking into account the existing theoretical approaches of scientists to the study of this problem, we will present the author's definition of neo-industrialization as a universal tool for creating an innovative economy through the implementation of a system of measures, conditions, and processes for the formation of a new industrial platform through the introduction of critical technologies to implement effective technological modernization. Moreover, the fact of considering neo-industrialization as a system of measures for the implementation of technological modernization of the economy allows us to highlight its key principles and properties. The most important systemic properties of neo-industrialization are: Integrity: The realization of the potential of each participant in the neo-industrial system in the implementation of its objective function; emergence: The possibility of the emergence of new qualities and properties of the system caused by the paradigm of neo-industrialization; functionality: Manifestations of specific functional features of elements of a neo-industrial system when interacting with environmental factors; structural: The ordering of the neo-industrial system, entailing the formation of a structured structure of interconnected elements in a certain way.

The most important parameters for the formation and implementation of the neo-industrialization paradigm in modern conditions are: Low productivity of the formation of interconnected chains of high-tech production; imperfection of the institutional framework for the implementation of neo-industrialization policies in economic systems; insufficient motivation of innovatively active business entities; insufficiency and imbalance of infrastructural support for the implementation of neoindustrial processes; and insufficient effectiveness of the formed mechanisms of neo-industrialization in modern conditions of socio-economic development.

At the same time, the fundamental principles of the formation of the neo-industrialization paradigm as the basis for the implementation of the innovative development scenario are: Stimulation of research, scientific, technical, innovative activity of economic systems; coordination of economic interests of participants in innovative and technological processes; strengthening the innovative and technical and technological potential of economic systems; training highly qualified personnel engaged in innovation; increasing the investment attractiveness of economic systems by increasing the added value of high-tech products; modernization of the industrial sector of the economy; implementation of strategic programs of innovative and scientific and technological development, etc. 
We may say that the innovation of the economy in the context of neo-industrialization implies the existence of a potential or real ability to carry out the process of commercialization in all spheres and sectors of the national economic system. "Usually, we think, neoindustrialization approaches building upon the region's assets will make more sense than simple, rootless re-industrialization strategy" [17]. As bright examples of the implementation of the neo-industrialization paradigm as the basis of the innovative trajectory of the development of economic systems at the regional level, we can consider Cambridge, Milton Keynes, Crawley, and Bracknel in the UK, Grenoble, Sophia Antipolis, and Saint-Quentin-en-Yvelines in France, Dortmund in Germany, Emilia-Romagna, and Lombardy in Italy, etc. "Many of these areas were insignificant provincial cities, with no industrial branches and high-technology industry, small and medium enterprises flourished in highly competitive international markets, and new products were produced which were characterized by design quality and short life cycles" [7]. If we talk about Russian experience at the local level, it is very curious to give an example of the Vinzavod Center for Contemporary Art in Moscow and the BelSU Research University in Belgorod, both of which are located on the basis of a repurposed industrial infrastructure facility that turned out to be unclaimed for its intended purpose. Moreover, there are trends in the direction of the wave flow of the fifth technological structure, "because manufacturing, information technology, and logistic have played a leading role since long, the local parties do their best now to create jobs in the interface of these sectors (such e-logistic and robotics) by investing in incubator centers and start-up promotion" [17].

Taking the official statistical data as the basis of the analysis (Russia in numbers. 2018: Brief statistical compilation), we analyze the volume of innovative goods, works, and services by constituent entities of the Russian Federation (Fig. 1).

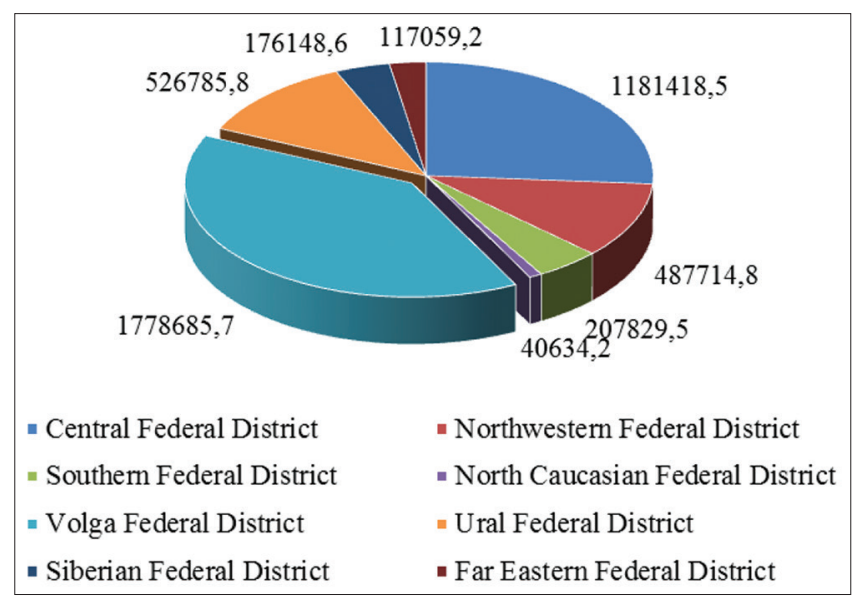

Figure 1: The amount of innovative goods, works, and services by constituent entities of the RF (Russian Industry) in 2018, thousand rubles

It is important to consider which types of innovation from the point of view of ongoing costs for technological innovation of organizations prevail (Fig. 2).

We have to say that from the point of view of studying the formation of the paradigm of neoindustrialization as the basis for the implementation of an innovative development scenario, the industry is most interesting, embodying innovative solutions in the real sector of the economy. "Hence, in the neoindustrialization discourse, high technology is never foreign to the capital-intensive manufacturing industry, and without goods-producing capacity, no knowledge, and high-tech design could be materialized into productive forces" [1].

An analysis of the conditions for the innovative development of economic systems today requires the identification and typologization of modern neoindustrialization trends: Compliance with intersectoral balances between the ratio of production volumes and costs of its implementation; stimulation of the innovation process to reduce production costs and increase labor productivity; increase in research and development costs; strengthening of specialization and cooperation of production; application of breakthrough technologies in production; intensification of processes of intellectualization of production; increasing requirements for the quality of professional training of specialists serving the production process at all stages; informatization and robotization of production processes; stimulating the integration of participants in industrial relations into various forms of integration associations, etc.

We are convinced that neo-industrialization as a phenomenon that occurs in response to the development of engineering and technology, scientific, and technological progress, it is advisable to consider as a set of key interrelated parameters that form a system of sources of potential economic growth, contributing to the implementation of an innovative scenario for economic development. "To stimulate the region's endogenous potential, now a bottom-up approach rather than top-down strategy was chosen for. Besides, coping with structural change in this district, the aim of the project was a modernization of institutions and the procedures of regional policy" [17].

To visualize the algorithm characterizing neoindustrialization as a process, we present in Fig. 3 a paradigm concept of the innovation of economic systems in the context of neo-industrial challenges, within the framework of which a mechanism has been formed for consolidating the parameters of neoindustrialization in accordance with the established imperatives of innovative development.

Analyzing presented concept of innovation of economic systems in the context of neo-industrial challenges on the Fig. 3, we note that the peculiarity of the formed approach is the justification for the transition from an export-raw model of the economic system to an innovative one. An important feature is 


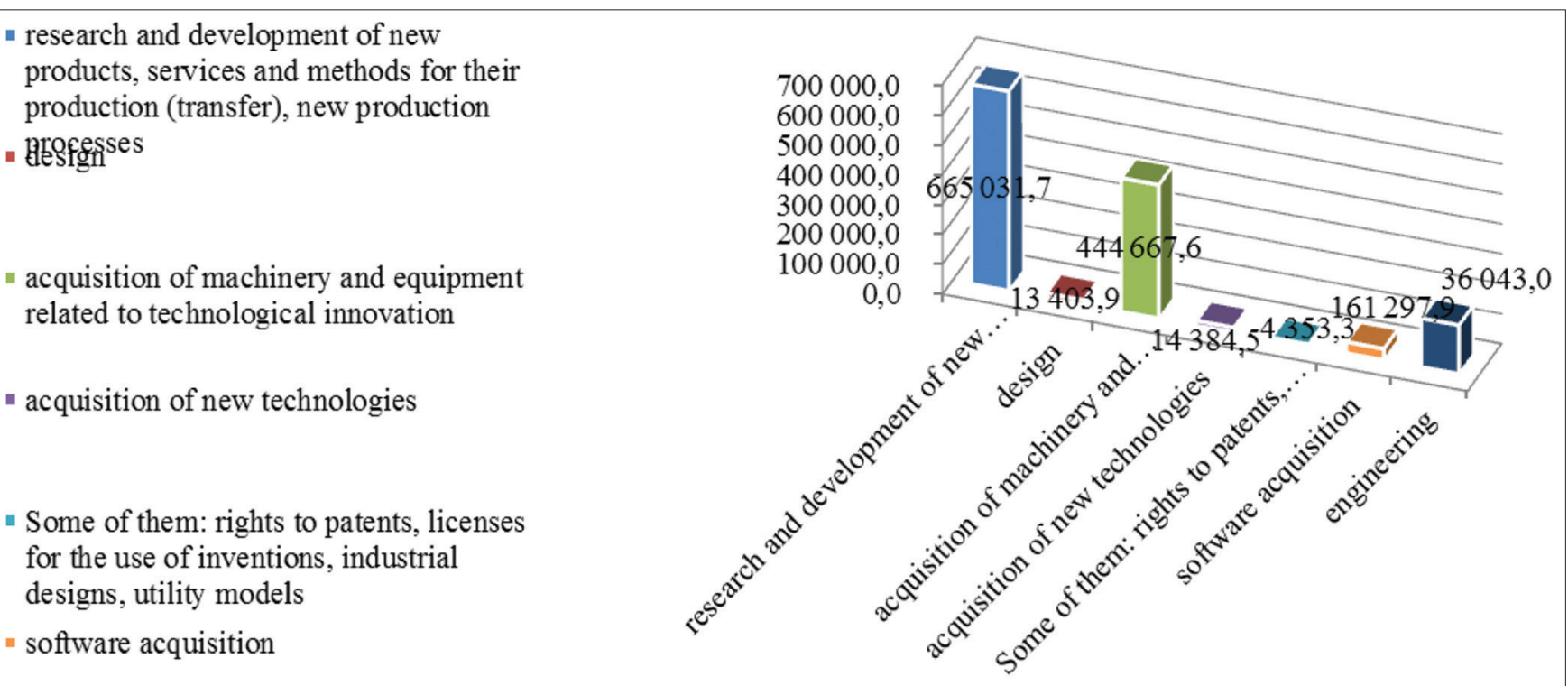

Figure 2: Costs of technological innovation of organizations by type of innovation in 2018

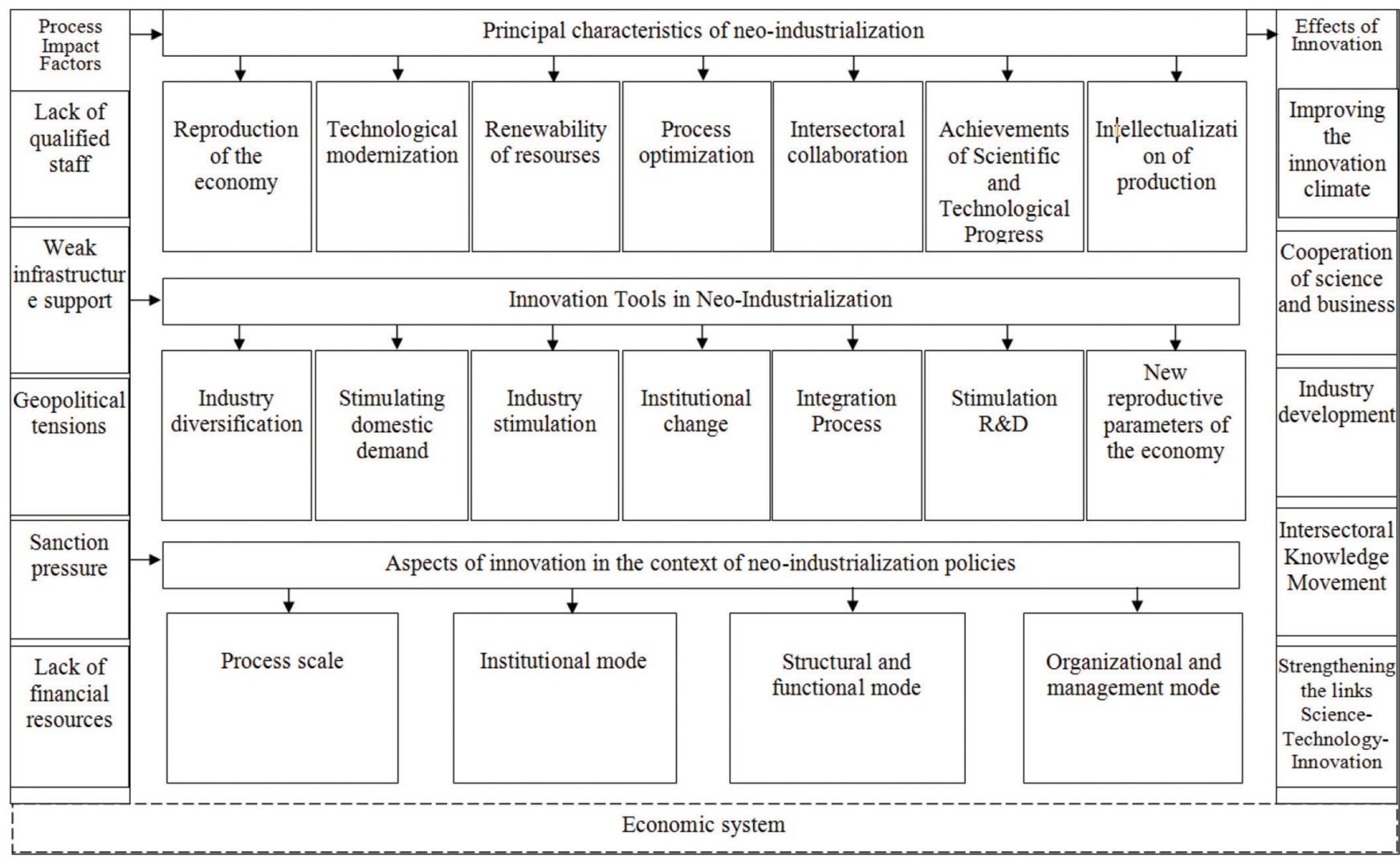

Figure 3: The paradigmatic concept of the innovation of economic system in the context of neo-industrial challenges (made by the authors)

the neo-industrialization policy and the need to take into account the trends in the transformation of material production and the real sector to activate them. In the presented concept, the principal characteristics of the implemented neo-industrialization policy in the Russian economy in modern conditions are noted. These include: Reproduction of the economy; technological modernization; renewable resources; optimization of technological processes; intersectoral interaction; achievements of scientific and technical progress; and intellectualization of production.
At the same time, the most important aspects were identified and the tools of innovation in the context of neo-industrial challenges were presented, namely: Industry diversification; stimulation of industrial production; stimulation of domestic demand; process integration; institutional change; R\&D promotion; and new reproductive parameters of the economy. Thus, the key aspects of innovation in the context of neoindustrialization policies are: The scale of processes; institutional nature; structural and functional nature; and structural and organizational nature. Note 
that the critical factors affecting the processes of economic innovation and the implementation of neoindustrialization policies in modern conditions are: Geopolitical tensions in the world; sanctions policy in relation to the Russian economy; poor infrastructure support for innovation processes; lack of financial resources; lack of qualified personnel, etc. The effects of the process of innovation in the conditions of the formation of a new industrial base include: Increasing the innovation climate; cooperation of science and business; development of industrial sectors; intersectoral movement of knowledge; strengthening the ties "science-technology-innovation," etc. We believe that the presented concept can be used in the process of forecasting economic growth, and in the innovative development of economic systems of various organizational levels of complexity in the context of neo-industrial challenges.

\section{Conclusion}

During the research, theoretical results were obtained, which makes it possible in the future to carry out an increment of scientific knowledge. "The strategies fall into two categories: Re-industrialization and neo-industrialization - with, as we will see, the last strategy being the most successful one" [17]. Thus, the hypothesis about the need to implement an innovative trajectory of the development of economic systems in the context of neo-industrialization policy is substantiated. The proposed concept of innovation in the conditions of neo-industrial challenges allows us to justify the mechanism for strengthening the potential of the industrial sector for economic development.

"It seems that a new macroeconomic cycle has opened, redefining core and peripheral regions, in which critical factors are innovation, technology transfer, industrial clustering, and the internationalization of local productive systems" [7]. The modern trends of neo-industrialization are identified and typologized to form an effective algorithm for implementing the innovative trajectory of economic systems development, taking into account neo-industrialization factors.

\section{Acknowledgment}

The study has been prepared as part of the basic part of the state task of the Ministry of Education and Science of Russia (0625-2020-0016).

\section{References}

1. Yu H. Information society with Chinese characteristics discursive evolution of the neo-industrialisation strategy in the people's daily. Javnost. 2008;15(3):23-38.

2. Alcácer V, Cruz-Machado V. Scanning the industry 4.0: A literature review on technologies for manufacturing systems. Eng Sci Technol Int J. 2019;22(3):899-919. https://doi.org/10.1016/j. jestch.2019.01.006

3. Dašić P. Scientific and Technological Trends: Selected Scientific-professional Papers (in Serbian). Vrnjačka Banja, Serbia: SaTCIP Publesher Ltd.; 2020

4. Kamble SS, Gunasekaran A, Gawankar SA. Sustainable Industry 4.0 framework: A systematic literature review identifying the current trends and future perspectives. Proc Saf Environ Protec. 2018;117:408-25. https://doi.org/10.1016/j.psep.2018.05.009

5. Karabegović I, Kovačević A, Banjanović-Mehmedović L, Dašić $P$, editors. Handbook of Research on Integrating Industry 4.0 in Business and Manufacturing. Hershey, Pennsylvania, USA: IGI Global; 2020. https://doi.org/10.4018/978-1-7998-2725-2

6. Oztemel E, Gursev S. Literature review of Industry 4.0 and related technologies. J Intell Manufact. 2020;31(1):127-82. https://doi.org/10.1007/s10845-018-1433-8

7. Komninos N, Sefertzi E. Neo-industrialisation and peripherality evidence from regions of Northern Greece. Geoforum. 1998;29(1):37-49. https://doi.org/10.1016/ s0016-7185(97)00019-5

8. Arzhanovskaya AV, Eltanskaya EA, Milovanova MV. Use of convergent technologies in education as an essential prerequisite for neo-industrialization of Russia. Lect Notes Netw Syst. 2020;110:395-9. https://doi.org/10.1007/978-3-030-45913-0_45

9. Biryukov VV, Romanenko EV. Economic behavior of business entities, culture and institutions: Specifics of their interrelations in conditions of neo-industrialization. Eur Res Stud J. 2017;20(4):370-85

10. InshakovaEI, KachalovRM, InshakovaAO. Russianand Eurasian technology platforms: Progress and challenges in accelerating the neo-industrialization processes. Lect Notes Netw Syst. 2020;110:31-40. https://doi.org/10.1007/978-3-030-45913-0_4

11. Inshakova El, Ryzhenkov AY, Inshakova AO. Neoindustrialization of the Russian economy: Technological and digital development. Stud Comput Intell. 2019;826:239-50. https://doi.org/10.1007/978-3-030-13397-9_28

12. Kovalev $\mathrm{Y}$, Sobolev A, Burnasov A. Industrialization, neoindustrialization and post-industrialism in the evolution of the old industrial region (On the example of saar-lor-lux euroregion). Sovremennaya Evropa. 2020;1:158-69. https://doi. org/10.15211/soveurope12020158169

13. Hassink R, Dong-Ho $S$. The restructuring of old industrial areas in Europe and Asia: Editorial. Environ Plann A. 2005;37:571-80.

14. Pipan T. Neo-industrialization models and industrial culture of small towns. GeoScape. 2018;12:10. https://doi.org/10.2478/ geosc-2018-0002

15. Zhironkin SA, Hasanov MA. Neo-industrial concept of structura transformations of the Russian economy. Bull Tomsk State Univ. Economy. 2014;4(28):14-24

16. Lentchuk EB, Filatov VI, Vlaskin GA, Ivanov AE, Smotritskaya II, Chernykh SI. New Industrialization as a Condition for the Formation of an Innovative Model for the Development of the Russian Economy. Scientific Report. Moscow, Russia: IE-RAS; 2013.

17. Hospers GJ. Regional Economic Change in Europe: A Neoschumpeterian Vision Volkswirtschaft. Vol. 3. Volkswirtschaft Series; 2004. 
18. Vasiliev NF. Neo-industrialization of the economy: Conditions for launch and implementation. Bull Inst Econ Res. 2016;1(1):49-63.

19. Banerjee AV. Notes towards a theory of industrialization in the developing world. In: Nirmala B, Marjit S, editors. Development, Displacement and Disparity: India in the Last Quarter of the Twentieth Century. Hyderabad, India: Orient Longman; 1997. p. 139-59.

20. Doroshenko YA, Malykhina IO, Somina IV. Methodology of the formation of a comprehensive support mechanism of innovation and investment development in the region. Lect Notes Netw Syst. 2020;128:916-23. https://doi. org/10.1007/978-3-030-46817-0_103

21. Romanova OA. The innovative component of the new industrialization. Bull Ural State Econ Univ. 2017;5(73):81-92.

22. Zernov IV, Proshkina LA. New industrialization of Russia as a prospect of economic growth: Problems and directions of development. Bull Penza State Univ. 2016;2(14):30-3.

23. Dašić $P$, Dašić J, Antanasković $D$, Pavićević N. Statistical analysis and modeling of global innovation index (GII) of Serbia. Lect Notes Netw Syst. 2020;128:515-21. https://doi. org/10.1007/978-3-030-46817-0_59

24. Tolkachev SA. Neo-industrial challenges of Russia's economic security. Ind Pol Conditions N Indust. 2015;1:225-36.

25. Bell D. The Upcoming Post-industrial Society. Experience of Social Forecasting. Moscow, Russia: Academia; 1999.
26. Doroshenko YA, Starikova MS, Somina IV, Malykhina IO. Improving the performance of high-tech companies based on interactions with subjects of the innovation environment. Reg Econ. 2019;15(4):1279-93.

27. Krasnyuk LV. Diagnostics of the stages of economic development and the formation of the neo-industrialization paradigm of Russian industry. Economics. 2016;1(235):158-66.

28. Sushkova IA. The Mechanism of Neo-industrialization: Justification Methodology. Vol. 13. Saratov, Russia: Izvestia Saratov University: New Ser Economy, Control, Law. 2013. p. 656-61.

29. Ermoshina TV. The role of investment and public-private partnerships in the neo-industrial economy. Intellect Innov Investment. 2015;3:26-31.

30. Grimsey D, Lewis MK. Evaluating the risks of public private partnerships for infrastructure projects. Int $\mathrm{J}$ Project Manag. 2002;20(2):107-18. https://doi.org/10.1016/ S0263-7863(00)00040-5

31. Hart O. Incomplete contracts and public ownership: Remarks, and an application to public-private partnerships. Econ J. 2003;113(486):C69-76. https://doi. org/10.1111/1468-0297.00119

32. Hodge GA, Greve C. Public-private partnerships: An international performance review. Public Adm Rev. 2007;67(3):545-58. https://doi.org/10.1111/j.1540-6210.2007.00736.x 